\title{
2 \\ EXPLORING THE IMMERSIVE JOURNALISM LANDSCAPE
}

\author{
Esa Sirkkunen, Jorge Vázquez-Herrero, Turo Uskali, \\ and Heli Väätäjä
}

Current drivers of 360-degree journalism have been mostly curious about the new medium, its possibilities, and are exploring business opportunities. The early adoption of such technology is often a matter of brand-building - that is, news organizations experimenting with virtual reality (VR) want to demonstrate that their digital strategies are forward-thinking (Watson 2017). After interviewing representatives from leading US newspapers, Bosworth and Sarah $(2019,226)$ also conclude, "among major media companies that failing to experiment in immersive and experimental stories will mean losing a race".

Thus far, 360-degree journalism has been generally a testbed for the most prominent media companies. For example, the BBC produced the very first entirely 360-degree TV episode of the technology program Click in March 2016. One crucial factor driving these experiments has been the activity of tech companies like Samsung and Google, who sponsored major journalistic institutions such as The New York Times and Euronews in 2017. Major platforms like Facebook and YouTube have already built platforms for 360-degree content with the possibility for users to publish content themselves. The process of platformization (Helmond 2015; Nieborg and Poell 2018) of 360-degree content and consumption is well underway.

This chapter starts with an overview of 360-degree journalism genres. We especially explore the relationship between conventional journalism and 360-degree productions. Our hypothesis is that the general narrative conventions and ethical principles of journalism are reflected in the evolving 360-degree journalism. We continue with questions regarding production and narration based on interviews with journalists making immersive journalism. We discuss suitable topics, production processes and narrative options concerning immersive journalism, especially 360degree journalism. The data for this chapter contains findings of projects in which we have analyzed more than 100 360-degree stories (Sirkkunen, Uskali, \& Väätäjä 2017 a,b; Vázquez-Herrero \& López-García 2017; Sirkkunen \& Vázquez-Herrero 
2018). We have analyzed the 360-degree journalism of CNN, USA Today, The New York Times, Euronews, the BBC, The Wall Street Journal, The Guardian, El País, and Dagens Nyheter. Additionally, we have interviewed 13 experts in immersive journalism from 2016 to 2019. Those interviewed come from the US (4), UK (1), Sweden (1), and Finland (7). Interviewees were chosen from various kinds of journalistic organizations (YLE, Helsingin Sanomat, Dagens Nyheter, the AP, Frontline), with a few people from VR production and gaming companies, tech companies, and academic teachers of VR. The interviews were done face-to-face, recorded, and conducted along a semi-structured questionnaire, each interview lasting 20 to 60 minutes.

\section{Evolving genres}

We have analyzed 360-degree content by topic, length, narration strategies, and immersive features in each 360-degree story. Analyzing various characteristics like sound, camera movement, and immersion, we wanted to grasp the multimodal (Kress 2010) affordances of 360-degree as a medium. From these findings, we built tentative genres of 360-degree journalism. We want to underscore that we are not trying to build a permanent taxonomy of 360-degree journalism. Our understanding of the genre concept highlights its unstable, dynamic nature (Kress 2010, 133). We have identified three tentative genres: 360-degree live, 360-degree news, and 360-degree documentaries. We will also touch briefly on the fourth genre, 360-degree fiction, when it is produced by media companies and disseminated on the same platforms as the journalistic pieces. We will give short descriptions of each genre in the following.

First, 360-degree live can be compared to live television or radio in that 360degree equipment transmits live footage, and the sound flows from an interesting environment. It gives users options to look around and obtain a full panorama of the event. For example, 360-degree live has been used to transmit NBA games and other sports events, concerts, town meetings, and political spectacles such as President Donald Trump's inauguration in 2016. However, live streaming in 360degree is not a genre solely for media houses. Moreover, user-generated 360degree live on YouTube, Periscope and Facebook is becoming increasingly popular (Schaerlaeckens 2017; Steinberg 2018; Cohen 2018).

Perhaps the most-produced genre of 360-degree journalism thus far is 360degree news. With a duration from one to three minutes, users can visit distant places, explore the wonders of nature and art exhibitions, or visit war zones and refugee camps. The most active newsroom has been The New York Times, which in 201618 produced 351 360-degree news pieces, following Euronews with 144 pieces (Sirkkunen \& Vázquez-Herrero 2018). Samsung sponsored both companies. The New York Times' project The Daily 360 was shot across 57 countries by 200 different journalists. According to The New York Times, the videos gathered 94 million views on Facebook and two million views on YouTube (Willens 2017). 
In our analysis, we found an interesting difference in storytelling between The New York Times and Euronews. Euronews has adopted 360-degree as part of their reporters' work process. This means Euronews reporters use narration more familiar from TV reporting, for example journalists' voiceover narration or reporting visibly on the spot. The New York Times chose a different path. The New York Times' reporting lets sources tell their stories and keeps the journalist mostly invisible and silent, as Figure 2.1 shows.

When analyzing 100 360-degree news videos by The New York Times and Euronews, we identified three different narration strategies (Sirkkunen \& VázquezHerrero 2018). Following Jones (2017), we call the first two reporter-led and sourceled narration (Figure 2.1). The first means the reporter is present either as a voiceover or visible in the footage. Source-led narration means the journalist/reporter is visually or vocally absent and a person tells his or her story as the only narrator. The third - also quite common - is to let the user see and hear the 360-degree content without significant interruptions from journalists or sources. We called this invisible/ neutral narration (Sirkkunen \& Vázquez-Herrero 2018). Notably, journalists partially control this third strategy by placing the camera, directing events, cutting footage and adding possible textual information or sounds.

The next subgenre is 360-degree documentaries (for example, Underworld: A Virtual Experience of the London Sewers or $6 \times 9$ by The Guardian) come close to extensive 2D documentaries regarding the amount of work and money spent on production. The duration of video documentaries varies and is mostly between four to 20 minutes. Compared to 360-degree news, more varied narrative strategies and styles are used.

Another offshoot worth mentioning is 360-degree fiction. Based on our observations, it is mainly The New York Times who has produced them. Of course, many other 360-degree production houses have focused on animated fiction, drama, or short fiction stories. As such, publishing fiction may be a wise move for
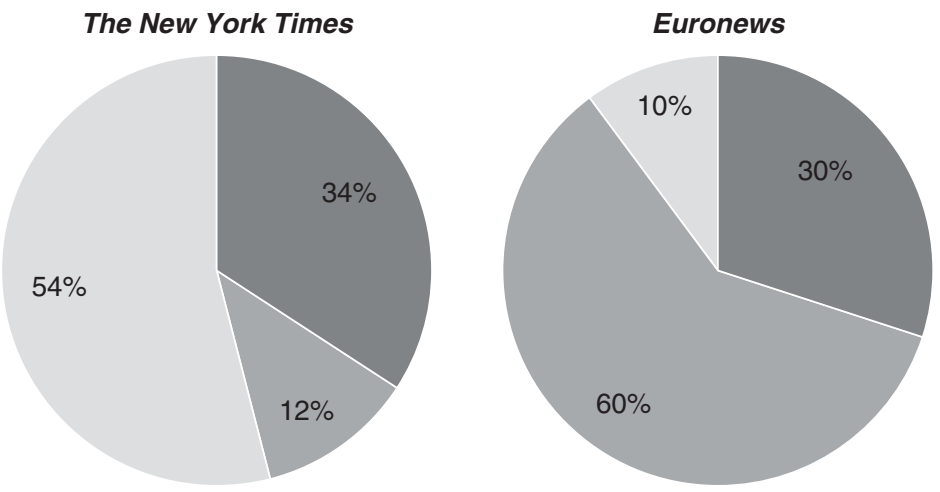

Invisible/neutral

Reporter

Source

FIGURE 2.1 Narration strategies of The New York Times and Euronews. 
a journalistic platform, because fiction broadens the scope of the content available and attracts new users to a company's VR content. Good examples of 360-degree fiction are Lincoln in the Bardo, a version of the novel by George Saunders, or $L A$ Noire short stories, in which a user is no casual observer but a character in a bar of 1940s' Los Angeles. Other examples of fiction content on 360-degree are Alento (RTVE) and Cervantes VR (RTVE). Interestingly, factual journalism and fiction have appeared on the same platform before, for example in the pre-history of modern journalism in the late 19th century, when novels and poems were published first as serial stories in newspapers and magazines.

As mentioned, the field is emerging, and borderlines between tentative genres are in flux. To illustrate this dynamically evolving field, we formed a fourfold table based on the importance of photorealistic effects (the visual representation of time and space of the news) in Figure 2.2. We placed genres evolving from photorealism (upper left) to emotional realism (in the center) and finally to fiction (lower right) to illustrate the differences and continuities between genres. The fourfold figure illustrates also the interaction between documentary and fiction genres - a process that has happened previously in the history of journalism, for instance in the early development of the television documentary (see, for example, Cutrin 1993).

In conclusion, in 360-degree live and 360-degree news the photorealistic tradition is more prevalent, while in 360-degree documentaries a wider array of narrative means is allowed. For example, in the beginning of spherical VR journalism, some prominent documentarists have been using animated characters and environments with real, on-the-spot audio recordings. One pioneer, Nonny de la Peña, has coined the concept of behavioral realism (de la Peña 2017, 2) to mean the sense of presence in the story is more important in creating authenticity for the photorealistic environment, for instance.

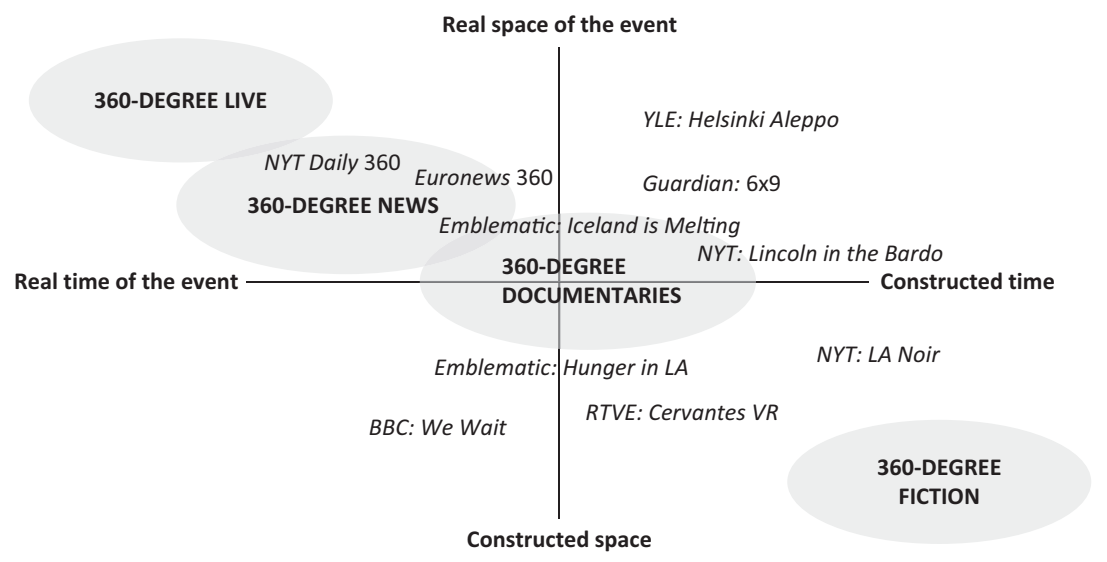

FIGURE 2.2 Some 360-degree productions illustrated fourfold. The figure depicts how different codes, canons of rhetoric and narration strategies are applied in different 360 journalism subgenres. 
Our genre analysis does not say much about the intentions and experiences of the actual creators of 360-degree journalism. To get more insight into such creations, we conducted a small number of expert interviews.

\section{Start with witness test}

In interviews, we focused on the process of making VR journalism concerning the following four themes: what kind of topics are suitable for VR journalism, what kind of staff is required for making VR, the principles of VR storytelling, and the main problems concerning the publication of VR stories. In the following, we introduce key findings from interviews and connect those to our content analysis results presented earlier and interviews published elsewhere.

In our analysis of Euronews, the topics in 360-degree news vary from Europe's politics and social problems such as climate change to human interest stories about exciting experiences in exotic environments. Topics in The NYT Daily included politics, but also more broadly social problems, minorities, culture and art in experientially interesting surroundings (Sirkkunen \& Vázquez-Herrero 2018).

How do VR professionals themselves define topics suitable for more immersive storytelling? There are various ways to make these decisions. For example, in CNN's newsroom, before starting to make a 360-degree story, journalists evaluate news topics using a pattern they call the witness test. Only topics in which the environment is interesting and creates strong experiences for users should be chosen. Jason Farkas from CNN emphasizes the importance of visceral experiences - for example, jumping out of planes or running with bulls in Pamplona (Watson 2017).

Ville Juutilainen, a journalist from the Finnish national broadcasting company YLE's Plus Desk, believes giving the user a presence in a new environment is the key to successfulVR/360-degree journalism. According to him, the same principle can be used in nearly all themes and topics, from sports to politics, the economy, or future urban visions. VR can be particularly useful in visualizations in which one must give users a sense of size or scale.

It is not only what you see but also from whose angle you see it. If we think about my making a VR story on how pedestrian crossings are insecure for children, I can make the adults look the same from a familiar place down here (from a child's perspective). We can literally play with different perspectives, which will definitely raise some questions.

Juutilainen 2017

Matilda Hanson from the Swedish newspaper Dagens Nyheter emphasizes the same feature of providing ways for users to perceive the news from different angles than they have normally used, which can be the very asset of VR journalism.

Therefore, it's very much the physical experience of almost a presence in these different areas of the world where people don't get to go normally. 
I think it is also a matter of transparency. We do not frame the way we do as photographers. [...] There's so much that we frame and so much that we cut out (in normal two-dimensional journalism) because we think this is the important story but, in a way, the readers miss out a lot of things that would make them empathise and understand the world better.

Hanson 2017

As with an interview (Willens 2017), The New York Times' Marcelle Hopkins, Executive Director of Virtual Reality, highlights the importance of interesting and extraordinary places that lure users to make a visit with 360-degree technology. She thinks that the environments work better than, for example, 360-degree interviews. When using the 360-degree headsets, users also appeared to stay longer exploring the 360-degree environment than watching the same material on flat video (Willens 2017).

Additionally, environments should have something extra for users to experience. Even by 2016, Paul Cheung, then from the AP, had learned that most of the happenings like fashion shows or exhibitions do not bring extra value when documented with 360-degree equipment. However, 2D footage is often sufficient for documenting these kinds of occasions in which the focus is fixed onstage. "The rule of thumb is 'would you look around you in a certain situation?' If the answer is yes, then maybe there is an opportunity to create a VR experience" (Brackebush 2016).

Duration is also an important factor. According to Paul Cheung, AP journalists have shifted to shorter news videos, as they seem to work better on social media platforms. However, this does not mean that long form is banned in AP, but longer stories are used, for example, in feature topics (Brackebush 2016).

As a summary of what makes good 360-degree journalism, we state that it is the ability to offer a strong feeling of presence and something to be perceived by the senses. Picking the right, interesting locations worth exploring is also crucial. The third important feature is the possibility of showing the world from an alternative or complementary point of experience. Good-quality sound and footage are also important factors to produce a sense of presence and immersion. A producer from the Finnish production house Zoan, Laura Ala states: "Sound creates easily a half of the virtual reality experience. It is a useful tool in guiding the users as it is in real life also" (Ala 2019; see also Bosworth \& Sarah 2019, 180-193).

\section{From simple to complicated work processes}

The consensus in the field is that VR operations are complicated and expensive. This is true with longer productions, but one can also start experiments with a lower budget. A good way to start inexpensively is to make shorter pieces first and then gradually expand into more complicated and longer productions. For example, Euronews has started to train its journalists to shoot 360-degree routinely, with only a short introduction. (See more in Chapter 7.) 
The process of making VR stories can sometimes be very slow. However, it need not necessarily be so. The 360-degree live cast is the fastest way to get content published on platforms like YouTube or Facebook. The 360-degree content can be quite a fast way to disseminate important news if there is a limited amount of postproduction. For example, the BBC already was able to use 360-degree footage in reporting the Bataclan terror attack in Paris 2015. Zillah Watson and her colleague filmed, edited, and published the footage on YouTube and Facebook within hours (Watson 2015).

Ole Krogsgaard from Euronews goes against the current wisdom, stating that interviews, when properly done, also can be interesting content in 360-degrees. Some prominent VR journalists have been avoiding 360-degree interviews, but Krogsgaard thinks that it can be a good and cost-effective way to expand the spectrum of 360-degree content. Euronews has also experimented with easy-to-use editing tools like web-basedVR editor Fader to lower the threshold for journalists to start editing more complicated stories themselves (Krogsgaard 2017 a,b,c).

There are also other VR strategies than Euronews" "keep it simple and cheap". Many of our interviewees have mostly been doing longer VR productions. Compared to documentaries made for TV, a VR documentary takes even more work because of the extra pre-planning and laborious post-production. Because the tools and programs used are developing rapidly and no general standards have developed yet, a wide variety of cameras, editing technologies, and programs are utilized. Many of the tools used come originally from game production like Unity, a development platform for multiplatform games and interactive contents. Hence, all kinds of new expertise and skills are needed when producing the content to VR.

Some companies make only a few VR productions per year. For example, PBS's Frontline program in the US has traditionally focused on investigative stories and documentaries. In 2015, it started to produce VR documentaries in collaboration with VR studio Emblematic Group, funded by the Knight Foundation (Wang 2015). In the interview, producer Benedict Moran explained that Emblematic Group has produced a couple of ten-minute-long VR documentaries per year (Moran 2016). In September 2019, the Frontline website contained 14 360-degree documentaries; the last (Greenland's Glaciers Are Melting Faster Than Expected) was published in September 2018.

Dagens Nyheter has started with a small VR staff and two full-time workers who get occasional help from other sections in the newsroom. DN started publishing VR stories in December 2016 and has published so far (at September 2019) 20 360-degree documentaries, each lasting from four to nine minutes.

In conclusion, concerning the use of staff, much, of course, depends on the general strategy and the resources. For example, Euronews can make a substantial amount of 360-degree news with relatively cheap equipment and short introductions to journalists on making 360-degree. Conversely, expensive documentaries like those by Emblematic Group have taken months to finish.

There are several open-ended questions for anyone considering starting a VR production. One substantial challenge is how to make content available to users. So 
far, one can apply several strategies. A news outlet can create an app to publish VR content. This is good in that the outlet can control its app, which is a more stable platform for more complex VR productions, but bad because it means users must download the app before perusing the story. The downloading process may be one hindrance to getting people to experience the content.

The news outlet can use already-existing VR platforms like Google's YouTube VR, Facebook's Oculus Rift, Samsung's GearVR, the HTCVive Headset, or Sony's PlayStation VR. Thus, making a version for each platform will add to production costs. Moreover, the platforms may take a share of the potential revenues derived from, for example, advertising connected to VR viewing. It is also unclear whether the tools of the big platforms are collecting user data.

Finnish journalists Ville Juutilainen and Jussi Pullinen both underscore that the whole process of making VR journalism should be based on open standards and platform independence.

Open technology solutions that are not parts of larger ecosystems are especially in the interest of national media companies [...] such equipment and technologies that you can use inside your own system without the risk of the information being transferred to somewhere outside.

Pullinen 2019

Thus far, one of the successful ways of making journalisticVR is to collaborate with a platform like Samsung GearVR and gather sponsors to cover expenses, as The New York Times does (more about this in Chapter 11).

According to journalism educator Robert Hernandez, the biggest bottleneck for adapting VR in newsrooms is the culture of fear, especially fear of the costs of producing VR.

The biggest problem that I see still is culture. Not necessarily accepting VR - I think there is a lot of acceptance of VR. But there is cultural fear of the cost of producing VR. And I encourage newsrooms to look the lowend cameras. To start producing those experiences, because there are a lot of things that you can learn in terms of where to place the camera, how to hide it, placing, framing, that you can do and learn on low-end cameras before you get in the high-end cameras, before you are going to immersive experiences, so it is not a lot of money to start. But a lot of people have that roadblock: oh my God, it costs tens, hundreds, thousands of dollars.

Hernandez 2017

\section{"Unlike traditional storytelling"}

One of our main findings from the content analysis has been that the longer and more developed 360-degree documentaries are more versatile concerning narrative structure (also Sánchez Laws \& Utne 2019). This means that, while some editors 
of longer documentaries remain within the photorealism convention, others have taken more liberties with animated characters and surroundings (de la Peña 2017). In those cases, credibility has been maintained, often with an authentic soundtrack or by carefully modelling and animating real circumstances. When technical affordances expand from 360-degree to more interactive ones, as is the case in volumetricVR, journalists have taken more freedom to explore ideas outside of standard documentary journalism.

One of the dilemmas that 360-degree andVR narration in general raise is how to balance the narrative function of journalism and the immersive effect that the technology affords. The sensory or affective thrill is not the only goal of immersive journalism; there is also an informational context to be given for the user to understand her experiences. Some signs of this dilemma are the aforementioned differences between the narration of Euronews and The New York Times' Daily 360 that we found in our analysis.

For journalists, it may take some time to understand the distinctions between writing linear text and writing for 360 and VR generally. Ville Juutilainen thinks that, at some point, writing for VR comes closer to writing game scripts than journalism. However, when writing stories, it is crucial to maintain journalistic principles. According to Juutilainen, there are assorted views and occasional disputes in the Finnish Broadcasting Company's graphics department on how photorealistic VR productions should be. The pioneering VR journalist Nonny de la Peña has argued that the full photorealistic illusion of reality is not the only prerequisite of credibility. Carefully crafted animations can give sufficiently good impressions of reality if the story is interesting and immersive (de la Peña 2017).

Jannicke Mikkelsen, a Norwegian visual journalist living in London, has shot and directed various VR documentaries with high-end equipment. One of her works is a VR documentary VR the Champions about the rock band Queen's concert in Barcelona, captured with a rig with 20 GoPro cameras and 70 microphones. She highlights the distinctions between VR and cinema narration.

It is very much unlike traditional storytelling. [...] One difference I've noticed is that I don't need establishing shots. I can just throw people into a situation. I don't have to say, like in the Queen film, this is a stadium and we are in Barcelona. Cut all that away. Just put them into their concert. It works better.

Mikkelsen 2017

According to Mikkelsen, VR the Champions works with few cuts because a concert is a familiar space and situation for users to experience and get ecstatic about the music and the band.

Noora Heiskanen has been working in a Finnish VR company, Teatime Productions, which produced the much-discussed 360-degree Helsinki Aleppo published by the national broadcasterYLE. It depicted how the center of Helsinki would look if it was destroyed as Aleppo was during recent years. Noora Heiskanen 
thinks that the novelty of VR lies simply in users' freedom to explore footage as they wish.

It is important to give enough space and time for the user to explore and accept that he/she can look elsewhere or to interpret the story differently. There has to be a good reason for usingVR production instead of traditional video. Maybe it is just that you do not have to follow a certain narrative.

Heiskanen 2017

One important feature is whether the narration - and technological affordances of the solution in question - give real agency to the user or whether he/she is a godlike figure who can only observe what is happening. So far, for example, the possibilities of interactivity in 360-degrees are very limited. Another technical restriction is the quite poor user experience that cheap cardboards may offer. There is the danger that users become disappointed with the poor quality and decide to avoid also high-end VR content in the future.

\section{Conclusions: different epistemologies for different genres}

During content analysis, we were able to detect several tentative genres: 360-degree live, 360-degree news, 360-degree documentaries, and 360-degree fiction. We found that different canons of documentary and narration strategies are utilized in different genres. For example, in short 360-degree news the journalistic code is very much based on the tradition of television news journalism, whereas in longer documentaries journalists are allowed more liberties - like using animated characters, building stylized environments, etc. We also found some justification for our hypothesis that general journalistic norms are reflected in immersive journalism. First, the topics chosen seemed to follow the journalistic canon used in news genres in general. Second, 360-degree live and short 360-degree news rely mostly on news realism and the photorealistic tradition. The tradition of photojournalism is also reflected in discussions as to whether it is allowed to edit footage and, if yes, how far the editing can go (see Aitamurto 2019). The discussion of realism shows that the defining process of immersive journalism is still very much in progress. On one hand, for example, Aitamurto (2019) emphasizes the importance of the realistic code of ethics of 360-degree news: in short, to represent what is rather than what if. Conversely, for instance, Sánchez Laws and Utne (2019) point out that journalists cannot claim authenticity regarding 360-degree content for synthetically reconstructed pieces. The credibility of stories like de la Peña's One Dark Night and Hunger in L.A. or The Guardian's $6 \times 9$ is, rather, based on the audience's trust in journalists and on the embodied cognition produced when using immersive journalism pieces (SánchezLaws \& Utne 2019).

It is still unclear if 360-degree technology will develop as a serious genre of immersive journalism. Importantly, after Samsung's sponsorship ended, the number 
of productions diminished dramatically, both in The New York Times and Euronews (Sirkkunen \& Vázquez-Herrero 2018). The peak year of producing 360-degree news by The New York Times (281) and Euronews (73) was 2017. In 2019, The New York Times made only a couple of 360-degree news articles, and Euronews about 20 .

As the declining figures show, it seems unlikely that short 360-degree news will soon become a major genre of immersive journalism. In addition, the viewer statistics on YouTube reveal that 360-degree has remained quite marginal compared to $2 \mathrm{D}$ news videos consumed simultaneously. However, the 360-degree technology has served as an important testbed for journalism and its core ideas and ideals.

Overall, it seems that VR indeed offers several new opportunities for journalistic storytelling, and 360-degree is the first linear step on that path. There may be an evolution in progress from eyewitnessing and experiencing visceral effects towards more complicated narrative elements found in games and fiction, including spherical sound and eventually more interactive VR features. With what kind of devices we will consume these new contents remains to be seen.

\section{References}

Aitamurto, T. 2019. "Normative Paradoxes in 360 Journalism: Contested Accuracy and Objectivity." New Media \& Society 21(1): 3-19.

Ala, L. 2019. Focus group discussion with VR experts, 25 February 2019, in Helsinki.

Bosworth, M. \& L. Sarah, 2019. Crafting Stories for Virtual Reality. New York: Oxford, UK: Routledge.

Brackebush, J. 2016. "What the Associated Press Has Learned from a Year of VR.” Digiday. https://digiday.com/media/aps-learned-vr-360-videos/ [Accessed 14 October 2019].

Cohen, A. 2018. "NBA's New Chinese Broadcast Deal with Migu Will Include Virtual Reality." Sporttechie.com. www.sporttechie.com/nba-chinese-broadcast-deal-migu-includesvirtual-reality/ [Accessed 1 September 2019].

Cutrin, M. 1993. "Packaging Reality: The Influence of Fictional Forms on the Early Development of Television Documentary." Journalism Monographs (137), February: 1-37.

de la Peña, N. 2017. "Towards Behavioral Realism: Experiments in Immersive Journalism." In: J.Aston, S. Gaudenzi, \& M. Rose (Eds.), I-Docs: The Evolving Practices of Interactive Documentary. New York; Chichester, UK: Columbia University Press pp. 206-221.

Hanson, M. 2017. Interview with Esa Sirkkunen, 10 May 2017, in Helsinki.

Heiskanen, N. 2017. Interview with Esa Sirkkunen, 15 March 2017, in Helsinki.

Helmond, A. 2015. "The Platformization of the Web: Making Web Data Platform Ready." Social Media + Society 1(2): 1-11.

Hernandez, R. 2017. Interview with Turo Uskali, 21 June 2017, in Vienna.

Jones, S. 2017. "Disrupting the Narrative: Immersive Journalism in Virtual Reality." Journal of Media Practice 18(2-3): 171-185. doi:10.1080/14682753.2017.1374677

Juutilainen,V. 2017. Interview with Esa Sirkkunen, 10 April 2017, in Helsinki.

Kress, G. 2010. Multimodality. New York: Routledge.

Kroksgaard, O. 2017a. "This Is How Euronews Trains Journalists in the 360." Medium. https://medium.com/journalism360/this-is-how-euronews-trains-journalists-in-36036cf663e4ea1 [Accessed 1 September 2019]. 
Kroksgaard, O. 2017b. "Experimenting with WebVR Fader and Interactive 360-degrees in a Newsroom." Medium. https://haptic.al/experimenting-with-webvr-fader-andinteractive-360-videos-in-a-newsroom-3f08ebcd710b [Accessed 1 September 2019].

Kroksgaard, O. 2107c. "Doing Interviews in 360 Degrees." Medium. https://medium.com/ journalism360/doing-interviews-in-360-videos-d3902f5c031 [Accessed 1 September 2019].

Mikkelsen, J. 2017. Interview with Esa Sirkkunen, 26 April 2017, in Tampere, Finland.

Moran, B. 2016. Interview with Turo Uskali, 26 September 2016, in Stanford, CA, USA.

Nieborg, D. \& T. Poell. 2018. "The Platformization of Cultural Production: Theorizing the Contingent Cultural Commodity.” New Media \& Society 20(11): 4275-4292.

Pullinen, J. 2019. Focus group discussion with VR experts, 2 May 2019, in Helsinki.

Sánchez Laws, A.L. \& T. Utne. 2019. "Ethics Guidelines for Immersive Journalism.” Frontiers in Robotics and AI. https://doi.org/10.3389/frobt.2019.00028

Schaerlaeckens, L. 2017. "Virtual Reality Is the Future of Soccer Broadcasting, and It's Already Here." Yahoo.com. https://sports.yahoo.com/news/virtual-reality-is-the-futureof-soccer-broadcasting-and-its-already-here-014744043.html [Accessed 1 September 2019].

Sirkkunen, E., T. Uskali, \& H.Väääjä. 2017a. "From Witnessing to Experiencing? Exploring the First Wave of 360-degree Journalism." Presented at the IAMCR World Conference, Cartagena, Colombia, 16-20 July 2017.

Sirkkunen, E., T. Uskali, \& H. Vääää. 2017b. "The Making of Journalistic VR: 'It Is Very Much Unlike Traditional Storytelling."” Presented at the Nordmedia Conference, Tampere, Finland, 17-19 August 2017.

Sirkkunen, E. \& J. Vázquez-Herrero. 2018. "Exploring the First Waves of VR-journalism." ECREA 2018, Lugano, 2 November 2018.

Steinberg, L. 2018. "Virtual Reality Is Leading the Sports-Tech Wave." Forbes.com. www. forbes.com/sites/leighsteinberg/2018/07/31/virtual-reality-the-forefront-of-the-techwave-sweeping-over-sports [Accessed 1 September 2019].

Vanian, J. 2017. "Google Is Experimenting with Virtual Reality Advertising." Fortune 500, 28 June 2017.http://fortune.com/2017/06/28/google-virtual-reality-advertising [Accessed 1 September 2019].

Vázquez-Herrero, J. \& X. López-García. 2017. "Immersive Journalism Through Mobile Devices: How Virtual Reality Apps Are Changing News Consumption.” In: Á. Rocha., A. Correia, \& H. Adeli et al. (eds.), Advances in Intelligent Systems and Computing 571. Cham, Switzerland: Springer, pp. 3-12.

Wang, S. 2015. "Frontline Is Diving Deeper into VR with $\$ 580,000$ from the Knight Foundation." Niemanlab.org. www.niemanlab.org/2015/12/frontline-is-diving-deeperinto-vr-with-580000-from-the-knight-foundation [Accessed 1 September 2019].

Watson, Z. 2015. "Filming 360-degrees in Paris." BBC News Labs Report.

Watson, Z. 2017. VR for News: The New Reality? Digital News Project. Oxford, UK: Reuters Institute for the Study of Journalism, University of Oxford. https://reutersinstitute.politics.ox.ac.uk/our-research/vr-news-new-reality [Accessed 15 March 2020].

Willens, M. 2017. “One Year in: What The New York Times Learned from Its 360-Degree Video Project,”'The Daily 360. Digiday. https://digiday.com/media/one-year-new-yorktimes-learned-360-degree-video-project-daily-360/ [Accessed 1 September 2019]. 